\title{
Comparison of survival and perioperative outcome of the colonic stent and the transanal decompression tube placement and emergency surgery for left-sided obstructive colorectal cancer: a retrospective multi-center observational study "The CODOMO study"
}

\author{
Shungo Endo ${ }^{1}$ (D) $\cdot$ K. Kumamoto ${ }^{1} \cdot$ T. Enomoto $^{2} \cdot$ K. Koizumi $^{3} \cdot$ H. Kato ${ }^{4} \cdot$ Y. Saida $^{2}$
}

Accepted: 19 November 2020 / Published online: 27 November 2020

(C) The Author(s) 2020

\begin{abstract}
Purpose Advances in endoscopic technology have led to the reevaluation of self-expandable metallic stent (SEMS) placement as a bridge-to-surgery (BTS) in patients with obstructive colorectal cancer. In Japan, after inclusion of SEMS placement as a BTS in the medical insurance coverage in 2012, this procedure has been increasingly performed. However, a transanal decompression tube (TADT) placement has been used as a BTS. We aimed to retrospectively evaluate the optimal strategy for obstructive leftsided colorectal cancer (OLCRC) by comparing SEMS and TADT placement with emergency surgery.

Methods We included 301 patients with stage II and III OLCRC from 27 institutions. The study patients were divided into Surgery group (emergency surgery, $n=103$ ), SEMS group (BTS by SEMS, $n=113$ ), and TADT group (BTS by TADT, $n=85$ ). We compared the survival and perioperative outcomes of patients in the Surgery group as a standard treatment with those in the SEMS and TADT groups.

Results The 3-year relapse-free survival rate in patients in the Surgery group was 74.8\%, while that in patients in the SEMS group and TADT group were $69.0 \%(p=0.39)$ and $55.3 \%(p=0.006)$, respectively. The technical success rate was not statistically different, but the clinical success rate was significantly higher in the SEMS group than in the TADT group $(p=0.0040)$. With regard to postoperative complications after curative surgery, the SEMS group had significantly lower of complications ( $\geq$ grade 2) than the Surgery group $(p=0.022)$.

Conclusion Patients who underwent SEMS placement for OLCRC had similar oncological outcomes to patients who underwent emergency surgery.
\end{abstract}

Keywords Obstructive colorectal cancer · Bridge to surgery · Self-expanding metallic stent · Transanal decompression tube · Emergency surgery

Shungo Endo

endoswing@gmail.com

1 Department of Coloproctology, Aizu Medical Center, Fukushima Medical University, Aizu-Wakamatsu City, Fukushima 969-3492, Japan

2 Department of Surgery, Toho University Ohashi Medical Center, Tokyo, Japan

3 Department of Gastroenterology, Tokyo Metropolitan Cancer Infectious Disease Center Komagome Hospital, Tokyo, Japan

4 Department of Clinical Laboratory and Endoscopy, Tokyo Women's Medical University, Medical Center East, Tokyo, Japan

\section{Introduction}

Colorectal cancer (CRC) is the most common cancer in the gastrointestinal tract in the world [1]. The incidence of obstruction in left-sided CRC was reported to be higher than that in right-sided CRC. Moreover, $8-16 \%$ of CRC patients initially present with bowel obstruction, which accounts for $85 \%$ of colonic emergencies [1,2]. Treatment for obstructive leftsided CRC (OLCRC) has been an emergency surgery including stoma creation for colonic decompression [3]. However, the emergency surgical procedure is associated with higher rates of mortality and morbidity compared to elective surgical procedure $[4,5]$. 
In Japan, transanal decompression tube (TADT) has been used as a decompression method to provide a bridge to surgery, which was first reported by Lelcuk et al. in 1985 [5]. Since there is solid stool matter in the dilated colon of patients with colonic obstruction due to left-sided CRC, TADT is not so effective, and management during decompression is complicated. Inevitably, placement of a tube from the anus also has a significant negative impact on the patient's quality of life (QOL) [6].

As self-expandable metallic stent (SEMS), which was first reported by Dohmoto et al. [7], has been covered by Japanese medical insurance in 2012, emergency operation and colonic stent have become a mainstream treatment for the obstructive CRC instead of TADT. However, "bridge to surgery" (BTS) by colonic stent is not recommended in the European guidelines proposed in 2014. Moreover, this guideline was reviewed and endorsed by the Governing Board of the American Society for Gastrointestinal Endoscopy (ASGE) [8]. We believe that the primary reason for this was due to the poor oncological outcome and many complications associated with stent placement in the cited literature. The Japan Colonic Stent Safe Procedure Research Group (JCSSPRG) has achieved lower complication rate in obstructive CRC by following their mini-guidelines, published on the JCSSPRG website [9]. We retrospectively evaluated the optimum strategy for OLCRC by comparing the oncologic and perioperative outcomes using SEMS and TADT with emergency surgery in Japan.

\section{Methods}

\section{Study design}

A retrospective multi-center observational study was conducted in the JCSSPRG. Twenty-seven institutions were invited to participate in this project. A case report form was used to collect cases from the participating institutions, from August 30, 2017, to July 30, 2019. The medical ethics committee of Fukushima Medical University reviewed and approved the observational study design and decided that the requirement for informed consent was not necessary owing to the observational design of the study. This study was registered in the Japan University Hospital Medical Information NetworkClinical Trials Registry (UMIN000024488).

To disseminate details about the colonic stent procedure to the participating facilities before the start of study, JCSSPRG launched a study group Web site (http://colon-stent.com/), posted the standard procedure as mini-guidelines (brief guidelines for safe placement of colonic stents), and held workshops to discuss a safe procedure for stent placement. The protocol of this study stated that participants would be referred the mini-guidelines. A video of each stent placement procedure was also uploaded to the Web site, accompanied by a written explanation as the characteristics of various stent are quite different. Postoperative complications were defined according to the Clavien-Dindo classification [10].

\section{Patient selection}

The subjects were patients with histologically proven stage II/ III left-sided colon or upper rectal cancer with obstruction, who underwent subsequent surgery with curative resection between January 2010 and December 2014. The definition of the obstruction was specified based on the ColoRectal Obstruction Scoring System (CROSS) [11], wherein patient's oral intake level is assessed as follows: CROSS 0, requiring continuous decompression; CROSS 1, no oral intake; CROSS 2 , liquid or enteral nutrient intake; CROSS 3, soft solids, lowresidue, and full diet with symptoms of stricture; or CROSS 4, soft solids, low-residue, and full diet without symptoms of stricture. CRC patients with CROSS score 0 and 1 were included in this study. The patient age ranged from 20 to 80 years. Patients treated with neoadjuvant chemotherapy and/or radiotherapy were excluded. Subsequently, 301 patients from 27 institutions met these criteria (Fig. 1). Patients were divided into three groups based on the decompression procedures: The Surgery group with decompression by colostomy or intraoperative decompression during radical surgery (emergency surgery, $n=103$ ), the SEMS group using SEMS for BTS (self-expanding metallic stent placement, $n=113$ ), and the TADT group with decompression using TADT for BTS (transanal decompression tube placement, $n=85$ ). The two-step surgery for curative resection for OLCRC is one of the techniques of bridging to surgery and thought to be standard treatment. Therefore, these cases (23cases, 22.3\%) were included in the Surgery group as a standard treatment. We compared the short-term and long-term outcomes of patients with the Surgery group to those with the SEMS and TADT groups, respectively. Since BTS using the TADT is not considered to be the standard treatment, we did not compare the SEMS with TADT groups except for their technical and clinical success rate. Moreover, BTS using the TADT thought going to be replaced by SEMS.

\section{Endpoints}

The primary endpoint was the relapse-free survival (RFS) duration on an intention-to-treat basis. RFS was defined as the time between curative surgery and the first relapse, death from any cause when no evidence of relapse was recorded, or the last date at which the patient was known to be free of disease.

The secondary endpoints were as follows:

1. Technical and clinical success rate of decompression using SEMS and TADT 
Fig. 1 Study design with the colonic obstruction management. CROSS sore, ColoRectal Obstruction Scoring System
Including criteria

1. Primary left-sided colorectal cancer (Stage II/III, location: Descending colon, Sigmoid colon, Upper rectum), January 2010 -Descember 2014

2. Colonic obstruction due to colorectal cancer with CROSS sore $0 / 1$

3. Age 20 - 80 year-old at radical surgery

4. Without neoadjuvant chemotherapy/radiotherapy

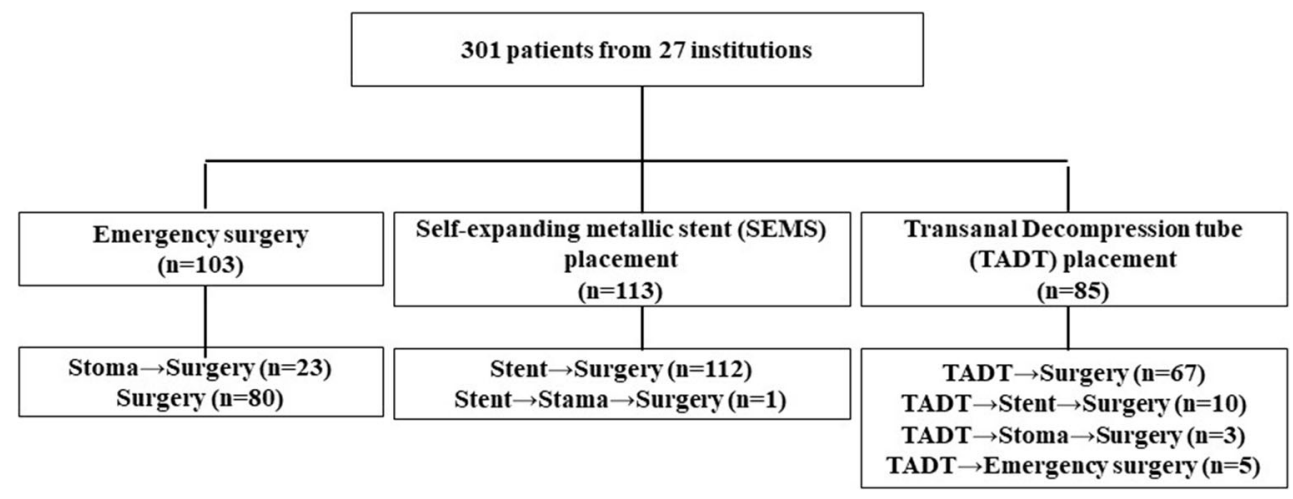

2. Adverse events during decompression

3. Postoperative complications after curative surgery

4. Temporary/permanent stoma rate after curative surgery

5. Induction rate of adjuvant chemotherapy

6. Decompression period, the length of a hospital stay after curative surgery and a total hospital stay

7. Primary recurrence sites and patterns

\section{Adjuvant chemotherapy and follow-up}

Japanese guidelines for the treatment of CRC [12] indicate that patients with stage III CRC are eligible for postoperative adjuvant chemotherapy; stage II CRC patients with obstruction may be eligible for adjuvant chemotherapy. Recommended therapies are as follows: (1) intravenous fluorouracil and levofolinate, (2) oral uracil and tegafur plus leucovorin, (3) capecitabine, and (4) 5-FU/folic acid combined with oxaliplatin (FOLFOX) 4 or modified FOLFOX6. However, the follow-up procedures and intervals followed local protocols.

\section{Statistical analysis}

Quantitative data were reported as median (range). All statistical analyses were performed using SPSS ver. 25 (IBM, Armonk, NY, USA). The Mann-Whitney $U$ test was used to compare continuous variables, and chi-square (Fisher's exact tests or Pearson's chi-square test) were used to compare discrete variables. RFS analysis was conducted using the Kaplan-Meier method and the log-rank test to determine significance of the survival curves. $P$ values less than 0.05 were considered statistically significant.

\section{Results}

\section{Patient characteristics}

The demographical characteristics of patients are summarized in Table 1. There were no significant differences in age and gender between the Surgery group and the SEMS/TADT group. The performance status (PS) was significantly lower in the SEMS group and the TADT group than the Surgery group ( $p=0.045, p=0.011$, respectively). The ratio of rectal cancer tended to be higher in the TADT group than the Surgery group $(p=0.061)$. No difference was found in the proportion of patients of stage II and III between the Surgery group and the SEMS group, although the rate of stage III was significantly higher in the TADT group than that of the Surgery group $(p=0.019)$. There was no statistically significant difference between the pretreatment serum CEA level of the Surgery group and the SEMS/TADT group.

\section{Primary endpoint}

The 3-year RFS rates were $74.8 \%$ in the Surgery group, $69.0 \%$ in the SEMS group, and $55.3 \%$ in the TADT group (Fig. 2). Although there was no statistically significant difference in RFS rate between the Surgery group and the SEMS group, the 3-year RFS rate of the TADT group was significantly lower than that of the Surgery group $(p=0.006)$. Subgroup analysis was performed with only colon cancer cases because the ratio of rectal cancer was tended to higher in the TADT group as mentioned above (Fig. 3). The 3-year RFS rates of patients with left-sided colon cancer (descending or sigmoid colon cancer) were $74.0 \%$ in the Surgery group, $68.9 \%$ in the SEMS group and $59.2 \%$ in the TADT group. There was no significant difference between the Surgery 
Table 1 Demographical characteristics of the study population
Fig. 2 Kaplan-Meier curves of relapse-free survival rates on an intension-to-treat basis in all cases. Surgery vs SEMS: $p=$ 0.39 , Surgery vs TADT: $p=$ 0.006 by log-rank test

\begin{tabular}{|c|c|c|c|c|c|}
\hline & \multirow{2}{*}{$\begin{array}{l}\text { Surgery group } \\
\text { (103 patients) } \\
\text { Number of } \\
\text { patients (\%) }\end{array}$} & \multirow{2}{*}{$\begin{array}{l}\text { SEMS group } \\
\text { (113 patients) } \\
\text { Number of } \\
\text { patients }(\%)\end{array}$} & \multirow[t]{2}{*}{$\begin{array}{l}P \text { value } \\
\text { (Surgery vs. } \\
\text { SEMS) }\end{array}$} & \multirow{2}{*}{$\begin{array}{l}\text { TADT } \\
\text { group (85 } \\
\text { patients) }\end{array}$} & \multirow[t]{2}{*}{$\begin{array}{l}P \text { value } \\
\text { (Surgery vs } \\
\text { TADT) }\end{array}$} \\
\hline & & & & & \\
\hline $\begin{array}{l}\text { Age (years) } \\
\text { median (range) }\end{array}$ & $67(28-80)$ & $69(48-80)$ & N.S & $69(52-80)$ & N.S \\
\hline Gender & & & N.S & & N.S \\
\hline Male & $64(62.1)$ & $69(61.1)$ & & $43(50.6)$ & \\
\hline Female & 39 (37.9) & $44(38.9)$ & & $42(49.4)$ & \\
\hline PS (ECOG) & & & $\begin{array}{l}0.045 \text { (PS } \\
0-1 \text { vs. PS } \\
2-4)\end{array}$ & & $\begin{array}{l}0.011 \text { (PS } \\
0-1 \text { vs. } \\
\text { PS 2-4) }\end{array}$ \\
\hline 0 & $68(66.0)$ & $69(61.1)$ & & $47(55.3)$ & \\
\hline 1 & $29(28.2)$ & $27(23.9)$ & & $22(25.9)$ & \\
\hline 2 & $5(4.6)$ & $7(6.2)$ & & $10(11.8)$ & \\
\hline 3 & 0 & $10(8.8)$ & & $4(4.7)$ & \\
\hline 4 & $1(1.0)$ & 0 & & $2(2.4)$ & \\
\hline Tumor location & & & $\begin{array}{l}\text { N.S (Colon } \\
\text { Vs. } \\
\text { Rectum) }\end{array}$ & & $\begin{array}{l}0.061 \\
\quad \text { (Colon } \\
\text { vs. } \\
\text { Rectum) }\end{array}$ \\
\hline Colon & $96(93.1)$ & $106(93.8)$ & & $71(83.6)$ & \\
\hline Descending & $25(24.3)$ & $19(16.8)$ & & $19(22.4)$ & \\
\hline Sigmoid colon & $71(68.9)$ & $87(77.0)$ & & $52(61.2)$ & \\
\hline Rectum & $7(6.8)$ & $7(6.2)$ & & $14(16.5)$ & \\
\hline Stage (TNM) & & & N.S & & 0.019 \\
\hline II & $63(61.2)$ & $64(56.6)$ & & $37(43.5)$ & \\
\hline III & $40(38.8)$ & $49(43.4)$ & & $48(56.5)$ & \\
\hline $\begin{array}{l}\text { CEA (ng/mL), } \\
\text { median (range) }\end{array}$ & $\begin{array}{l}5.7 \\
\quad(1.2-495 .- \\
3)\end{array}$ & $\begin{array}{l}5.8 \\
\quad(1.1-174- \\
.3)\end{array}$ & N.S & $7.3(1.4-111.0)$ & N.S \\
\hline $\begin{array}{l}\text { Follow up period } \\
\text { (months), } \\
\text { median (range) }\end{array}$ & $\begin{array}{l}56.2 \\
\quad(1.2-92.1)\end{array}$ & $\begin{array}{l}46.2 \\
\quad(4.2-78 .- \\
2)\end{array}$ & N.S & $48.9(0.2-93.2)$ & N.S \\
\hline
\end{tabular}

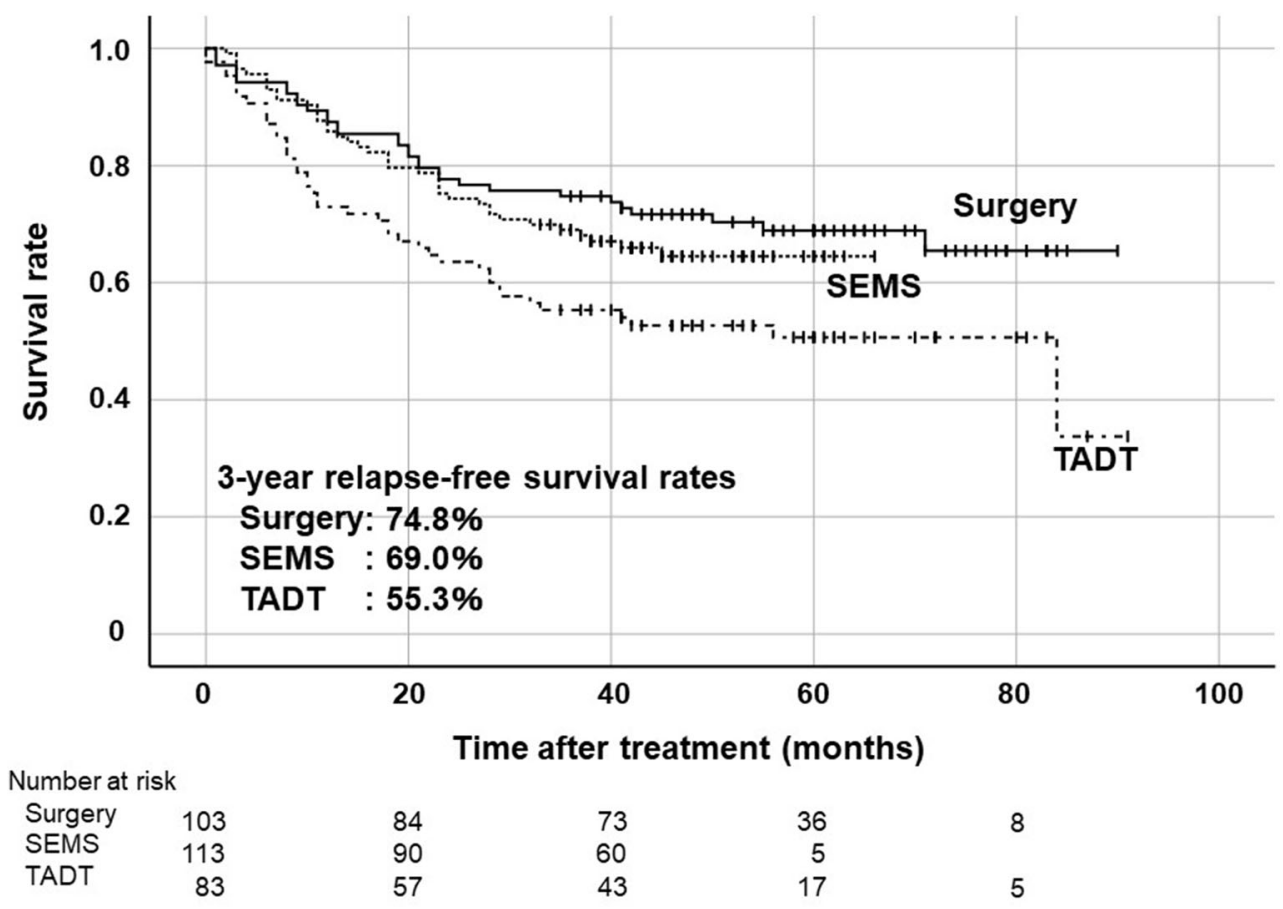


Fig. 3 Kaplan-Meier curves of relapse-free survival rates on an intension-to-treat basis in location of descending colon and sigmoid colon. Surgery vs SEMS: $p=$ 0.47 , Surgery vs TADT: $p=0.06$ by log-rank test

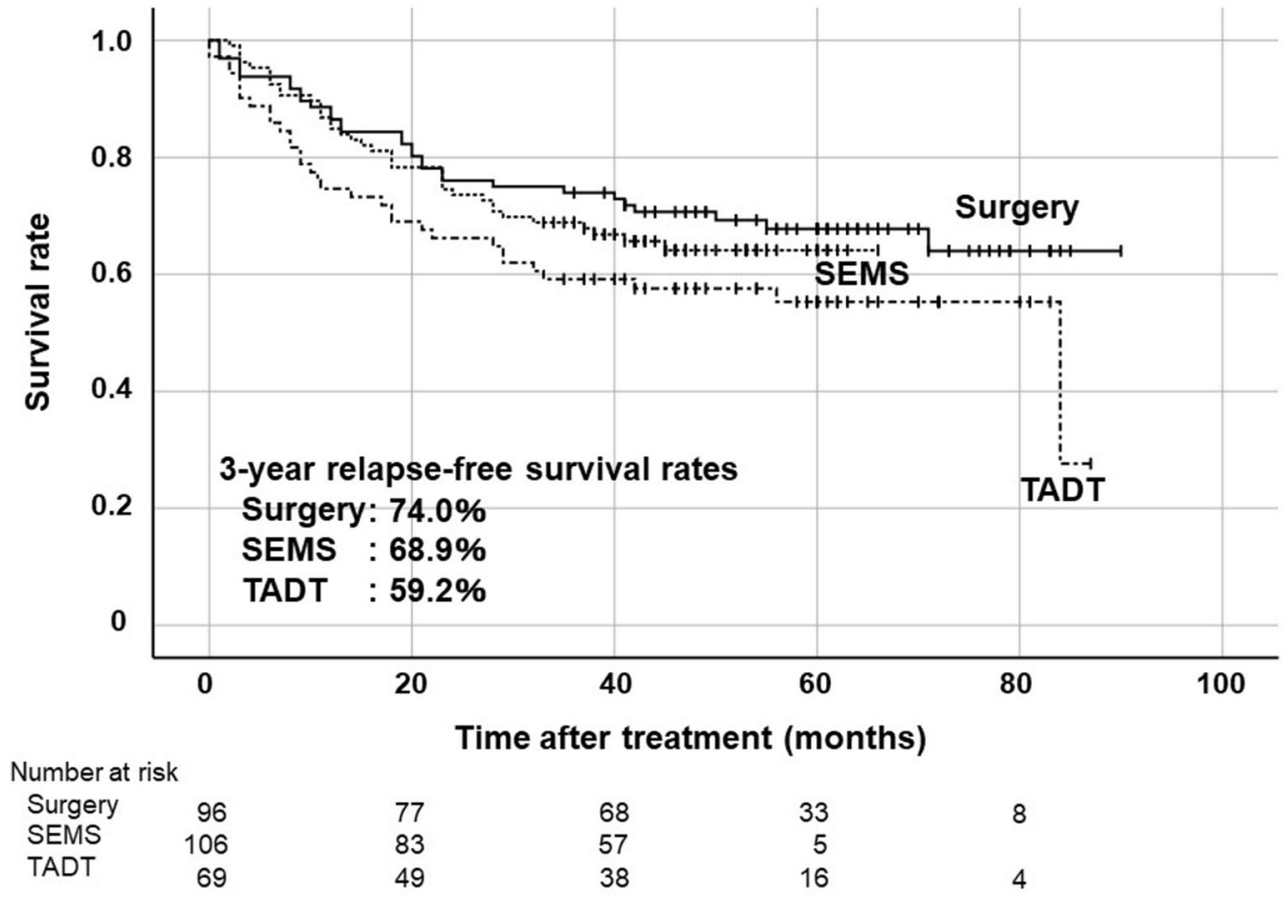

group and the SEMS group, and the TADT group was relatively lower than the Surgery group $(p=0.06)$. The 3-year RFS rates of patients with stage II were $74.6 \%, 75.0 \%$, and $59.5 \%$ in the Surgery group, SEMS and TADT groups, respectively (Fig. 4a). The 3-year RFS rates of patients with stage III were $75.0 \%, 61.2 \%$, and $52.1 \%$ in the Surgery, SEMS, and TADT groups, respectively (Fig. 4b). No significant difference between the Surgery group and the SEMS/ TADT group was observed in patients with stage II. RFS in

\section{a Stage II}

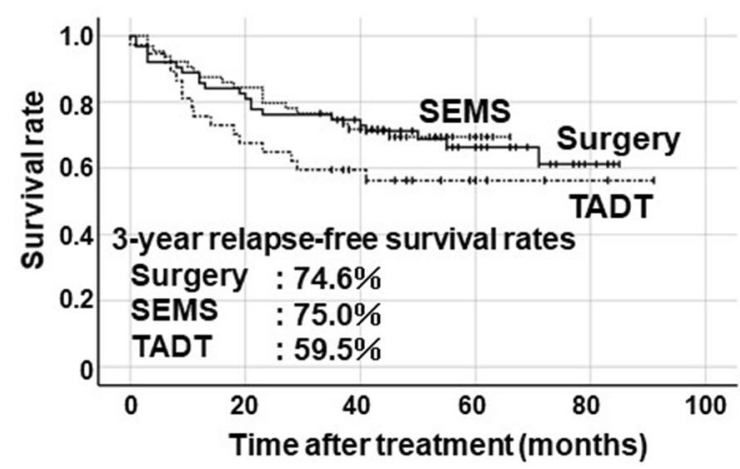

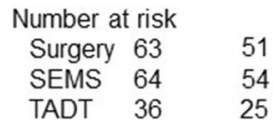

stage III patients with the TADT group was significantly lower than that in patients with the Surgery group $(p=0.013)$.

\section{Secondary endpoints}

Technical success rate was not statistically different between the SEMS group: (99.1\%) and the TADT group (94.1\%), but clinical success rate was significantly higher in the SEMS group $(97.3 \%)$ compared with the TADT group $(85.9 \%)$ $(p=0.004)$ (Table 2). There was no difference in complication

\section{b Stage III}

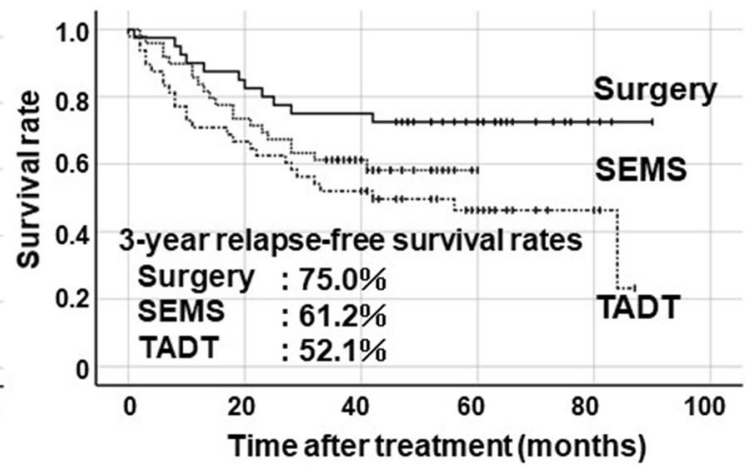

$\begin{array}{llllll}\text { Number at risk } & & & & \\ \text { Surgery } & 40 & 33 & 30 & 17 & 3 \\ \text { SEMS } & 49 & 36 & 20 & 0 & \\ \text { TADT } & 47 & 32 & 2 & 1 & \\ & & & 4 & 1 & 3\end{array}$

Fig. 4 Kaplan-Meier curves of relapse-free survival rates on an intension-to-treat basis in Stage II and Stage III. Surgery vs SEMS: $p=0.87$, Surgery vs TADT: $p=0.23$ in Stage II by log-rank test (a), Surgery vs SEMS: $p=0.16$, Surgery vs TADT: $p=0.013$ in Stage III in log-rank test (b) 
rates during decompression including perforation, migration and re-obstruction between the SEMS group and the TADT group. The number of cases requiring emergency surgery was significantly higher in the TADT group than the SEMS group $(p=0.009)$.

Treatment characteristics of the study population are shown in Table 3. Comparison of the SEMS group and the Surgery group showed that the rate of laparoscopic procedure was significantly higher in the SEMS group $(p<0.0001)$, temporary/permanent stoma rate was significantly lower in the SEMS group $(p<0.0001)$, and final permanent stoma rate was lower in the SEMS group $(p=0.008)$. There was no difference in these rates between the Surgery group and the TADT group. There were no significant differences in depth of invasion between the Surgery group and the SEMS/TADT group, and the ratio of positive lymph node metastasis cases were significantly higher in the TADT group than the Surgery group $(p=0.021)$. The number of harvested lymph nodes was higher in SEMS group than the Surgery group $(p<0.001)$, while there was no difference between Surgery group and TADT group. When the proportion of patients who received adjuvant chemotherapy was compared between stage II and stage III, there were no difference between the treatment groups.

The decompression period and the hospitalization are shown in Table 4. In the Surgery group, the decompression period was calculated in patients who underwent radical surgery after stoma creation. The postoperative hospital stay was significantly shorter in the SEMS group and the TADT group than the Surgery group ( $p<0.0001, p=0.038$, respectively). These facts were manifested in the results that the total combined hospital stay for the decompression and postoperative period was significantly shorter in the SEMS group than in the Surgery group $(p=0.048)$.

Postoperative complications after curative surgery were classified using the Clavien-Dindo classification (Table 5). Total number of complications ( $\geq$ grade 2 ) after curative surgery were significantly lower in the SEMS group than the Surgery group $(p=0.022)$, while there was no statistical difference between the Surgery group and the TADT group. The occurrence of postoperative ileus ( $\geq$ grade 3 ) was significantly higher in the SEMS group than the Surgery group ( $p=$ $0.03)$.

The sites of recurrence are shown in Table 6. There was no statistically difference in total recurrence rate between the SEMS group and the Surgery group $(p=0.088)$, while in the TADT group was significantly higher than that in the Surgery group $(p=0.006)$. There was no statistically difference in the peritoneal recurrence rates between three groups. The hematogenous metastases, to the liver, lung and brain, were found in 11 cases $(10.7 \%)$ of the Surgery group, 21 cases $(18.6 \%)$ of the SEMS group, and 17 cases $(20.0 \%)$ of the TADT group. Although the frequency of the hematogenous metastases in the TADT group was more common than that in the Surgery group, the difference was not statistically significant.

\section{Discussion}

In the present study, we clarified that short-term and longterm outcomes of patients with SEMS placement for OLCRC were acceptable when compared with those of patients who underwent emergency surgical procedure. SEMS placement as BTS for curative treatment of obstructive CRC was not recommended as a standard treatment in the European Society of Gastrointestinal Endoscopy (ESGE) guidelines in 2014 [8]. This guideline was based on studies that reported a lower technical success rate of SEMS insertion for a small number of cases about 10 years earlier [13, 14]. However, after the ESGE guideline, many studies, including meta-analyses, have investigated long-term outcomes following SEMS placement compared with emergency resection. According to these reports, no significant survival difference was observed between treatment groups. Most of these studies were retrospective and underpowered, they seldom had recurrence and survival as the primary outcome measures, and follow-up period was often relatively short. Subsequently, reports from Japan [15], South Korea
Table 2 Technical and clinical success rates and complications during decompression

\begin{tabular}{llll}
\hline & $\begin{array}{l}\text { SEMS group (113 } \\
\text { patients) } \\
\text { Number of patients (\%) }\end{array}$ & $\begin{array}{l}\text { TADT group (85 } \\
\text { patients) } \\
\text { Number of patients (\%) }\end{array}$ & $\begin{array}{l}P \\
\text { value }\end{array}$ \\
\hline Technical success rate & $112(99.1)$ & $80(94.1)$ & N.S \\
Clinical success rate & $110(97.3)$ & $73(85.9)$ & 0.004 \\
Complications during decompression & $2(1.8)$ & $2(2.4)$ & N.S \\
$\begin{array}{l}\text { Perforation } \\
\text { Migration }\end{array}$ & 0 & $5(5.9)$ & \\
$\begin{array}{l}\text { Re-obstruction } \\
\text { Emergency operation during } \\
\text { decompression }\end{array}$ & $1(0.9)$ & 0 & 0.009 \\
\hline
\end{tabular}


Table 3 Treatment characteristics of the study population

\begin{tabular}{|c|c|c|c|c|c|}
\hline & $\begin{array}{l}\text { Surgery group } \\
(103 \text { patients) } \\
\text { Number of } \\
\text { patients }(\%)\end{array}$ & $\begin{array}{l}\text { SEMS group } \\
\text { (113 patients) } \\
\text { Number of } \\
\text { patients }(\%)\end{array}$ & $\begin{array}{l}P \text { value } \\
\text { (Surgery } \\
\text { vs. SEMS) }\end{array}$ & $\begin{array}{l}\text { TADT group } \\
\text { ( } 85 \text { patients) } \\
\text { Number of } \\
\text { patients }(\%)\end{array}$ & $\begin{array}{l}P \text { value } \\
\text { (Surgery } \\
\text { vs. TADT) }\end{array}$ \\
\hline Surgical approach & & & $<0.0001$ & & $<0.0001$ \\
\hline $\begin{array}{l}\text { Open } \\
\text { Laparoscopic }\end{array}$ & $\begin{array}{l}100(97.1) \\
3(2.9)\end{array}$ & $\begin{array}{l}57(50.4) \\
56(49.6)\end{array}$ & & $\begin{array}{l}64(77.1) \\
21(24.7)\end{array}$ & \\
\hline \multicolumn{6}{|l|}{ Stoma } \\
\hline Temporary/permanent & $47(45.6)$ & $6(5.3)$ & $<0.0001$ & $27(31.8)$ & N.S \\
\hline Permanent & $11(10.7)$ & $2(1.8)$ & 0.008 & $15(17.6)$ & N.S \\
\hline $\begin{array}{l}\text { Depth of invasion } \\
\text { (TNM) }\end{array}$ & & & N.S & & N.S \\
\hline $\mathrm{T} 2$ & 0 & $1(0.9)$ & & 0 & \\
\hline $\mathrm{T} 3$ & $58(56.3)$ & $81(71.7)$ & & $48(56.5)$ & \\
\hline $\mathrm{T} 4 \mathrm{a}$ & $33(32.0)$ & $23(20.4)$ & & $29(34.1)$ & \\
\hline $\mathrm{T} 4 \mathrm{~b}$ & $12(11.7)$ & $8(7.1)$ & & $8(9.4)$ & \\
\hline $\begin{array}{l}\text { Lymph node } \\
\text { metastasis (TNM) }\end{array}$ & & & N.S* & & $0.021^{*}$ \\
\hline No & $63(61.2)$ & $64(56.6)$ & & $37(43.5)$ & \\
\hline N1 & $36(35.0)$ & $35(31.0)$ & & $38(44.7)$ & \\
\hline $\mathrm{N} 2$ & $4(3.9)$ & $14(12.4)$ & & $10(11.8)$ & \\
\hline \multicolumn{6}{|l|}{ Stage (TNM) } \\
\hline IIA & $31(30.1)$ & $53(46.9)$ & & $16(19.0)$ & \\
\hline IIB & $23(22.3)$ & $9(8.0)$ & & $16(19.0)$ & \\
\hline IIC & $9(8.7)$ & $2(1.8)$ & & $5(5.9)$ & \\
\hline IIIA & 0 & $1(0.9)$ & & 0 & \\
\hline IIIB & $36(35.0)$ & $35(31.0)$ & & $39(45.9)$ & \\
\hline IIIC & $4(3.9)$ & $13(11.5)$ & & $9(10.6)$ & \\
\hline $\begin{array}{l}\text { Number of harvested } \\
\text { lymph nodes, mean } \\
\text { (range) }\end{array}$ & $16(0-49)$ & $22(7-106)$ & $<0.0001$ & $18(3-80)$ & N.S \\
\hline \multicolumn{6}{|l|}{ Adjuvant chemotherapy } \\
\hline Stage II & $17(27.0)$ & $21(32.8)$ & N.S & $13(35.1)$ & N.S \\
\hline Stage III & $30(75.0)$ & $31(63.3)$ & N.S & $36(75.0)$ & N.S \\
\hline
\end{tabular}

*Pearson's chi-square test
[16], Italy [17], Netherlands [18], and a meta-analysis on short-term outcome [19], showed good success rates of SEMS placement. Another meta-analysis [20] reported that patients with SEMS placement were not inferior to those with emergency surgery in terms of short-term and longterm outcomes. In view of new evidences, the ESGE
Table 4 Decompression periods and hospital stays

\begin{tabular}{llll}
\hline & $\begin{array}{l}\text { Surgery group (103 } \\
\text { patients) }\end{array}$ & $\begin{array}{l}\text { SEMS group (113 } \\
\text { patients) }\end{array}$ & $\begin{array}{c}\text { TADT group (85 } \\
\text { patients) }\end{array}$ \\
\hline $\begin{array}{l}\text { Decompression period (day), mean } \\
\text { (range) }\end{array}$ & $57.0(1-396)^{*}$ & $17.0(2-84)$ & $10.0(0-43)$ \\
$\begin{array}{l}\text { Hospital stay after curative surgery } \\
(\text { day), mean (range) }\end{array}$ & $16.0(7-225)$ & $11.0(5-62)^{* *}$ & $14.0(6-167)^{* *}$ \\
Total hospital stay (day), mean (range) & $28.0(7-225)$ & $23.0(8-81)^{\dagger}$ & $28.0(10-171)$ \\
\hline
\end{tabular}

*Decompression period of the Surgery group was calculated by cases decompression of stoma before curative surgery

**Hospital stay after curative surgery were shorter in the SEMS group and the TADT group than the Surgery group ( $p<0.0001, p=0.038$, respectively)

${ }^{\dagger}$ Total hospital stay was shorter in the SEMS group than the Surgery group $(p=0.048)$ 
Table 5 Postoperative complications after curative surgery

\begin{tabular}{|c|c|c|c|}
\hline & $\begin{array}{l}\text { Surgery group (103 } \\
\text { patients) } \\
\text { Number of patients }\end{array}$ & $\begin{array}{l}\text { SEMS group (113 } \\
\text { patients) } \\
\text { Number of patients }\end{array}$ & $\begin{array}{l}\text { TADT group ( } 85 \\
\text { patients) } \\
\text { Number of patients }\end{array}$ \\
\hline Complication $(\geq \mathrm{G} 2)$ (yes:no) & $36: 67$ & $23: 90 *$ & $25: 60$ \\
\hline $\begin{array}{l}\text { Superficial incisional SSI } \\
\quad(\mathrm{G} 2: \geq \mathrm{G} 3)\end{array}$ & $8: 0$ & $3: 0$ & $5: 0$ \\
\hline Deep incisional SSI (G2: $\geq \mathrm{G} 3$ ) & $0: 1$ & & \\
\hline Space/organ SSI (G2: $\geq \mathrm{G} 3)$ & $1: 0$ & $1: 0$ & $1: 1$ \\
\hline $\begin{array}{l}\text { Anastomotic leakage } \\
(\mathrm{G} 2: \geq \mathrm{G} 3)\end{array}$ & $4: 6$ & $2: 5$ & $2: 2$ \\
\hline $\begin{array}{l}\text { Anastomotic hemorrhage } \\
\qquad(\mathrm{G} 2: \geq \mathrm{G} 3)\end{array}$ & & $0: 2$ & \\
\hline $\begin{array}{l}\text { Anastomotic stenosis } \\
\quad(\mathrm{G} 2: \geq \mathrm{G} 3)\end{array}$ & & $0: 1$ & \\
\hline Ileus $(\mathrm{G} 2: \geq \mathrm{G} 3$ ) & $8: 0$ & $1: 6^{* *}$ & $4: 1$ \\
\hline $\begin{array}{l}\text { Necrotic/ischemic enteritis } \\
(G 2: \geq G 3)\end{array}$ & $0: 1$ & $0: 1$ & $2: 0$ \\
\hline Pneumonia $(\mathrm{G} 2: \geq \mathrm{G} 3)$ & $3: 0$ & & $0: 1$ \\
\hline $\begin{array}{l}\text { Incisional abdominal hernia } \\
\quad(\mathrm{G} 2: \geq \mathrm{G} 3)\end{array}$ & $0: 1$ & $0: 1$ & \\
\hline Thrombosis $(\mathrm{G} 2: \geq \mathrm{G} 3)$ & $0: 1$ & & \\
\hline Cholecystitis (G2: $\geq \mathrm{G} 3$ ) & $1: 1$ & $0: 1$ & $2: 0$ \\
\hline Sepsis $(\mathrm{G} 2: \geq \mathrm{G} 3)$ & & & $0: 1$ \\
\hline Renal failure $(\mathrm{G} 2: \geq \mathrm{G} 3)$ & $1: 0$ & & \\
\hline Arrhythmia (G2: $\geq \mathrm{G} 3)$ & $0: 1$ & & \\
\hline $\begin{array}{l}\text { Gastrointestinal perforation } \\
(\mathrm{G} 2: \geq \mathrm{G} 3)\end{array}$ & & & $0: 1$ \\
\hline Others $(\mathrm{G} 2: \geq \mathrm{G} 3)$ & $1: 0$ & $4: 0$ & $2: 1$ \\
\hline
\end{tabular}

*All complications $(\geq \mathrm{G} 2)$ were lower in the SEMS group than the Surgery group $(p=0.022)$

**Ileus $(\geq \mathrm{G} 3)$ was higher in the SEMS group than the Surgery group $(p=0.030)$

Guideline was up-dated in April 2020 and recommended the use of SEMS in the treatment of malignant colonic obstruction [21]. Further, ESGE also recommends that colonic stenting should be performed or directly supervised by an operator who has competence in both colonoscopy and fluoroscopic techniques and who performs colonic stenting on a regular basis. Our study was inspired by these results and our results were in accordance with the guidelines.

Table 6 Sites of recurrence

\begin{tabular}{llll}
\hline & $\begin{array}{l}\text { Surgery group (103 } \\
\text { patients) } \\
\text { Number of patients (\%) }\end{array}$ & $\begin{array}{l}\text { SEMS group (113 } \\
\text { patients) } \\
\text { Number of patients (\%) }\end{array}$ & $\begin{array}{l}\text { TADT group (85 } \\
\text { patients) } \\
\text { Number of patients (\%) }\end{array}$ \\
\hline Liver & $8(7.8)$ & $16(14.2)$ & $9(10.6)$ \\
Lung & $2(1.9)$ & $5(4.4)$ & $11(12.9)$ \\
Peritoneum & $4(3.9)$ & $6(5.3)$ & $8(9.4)$ \\
Lymph node & $3(2.9)$ & $6(5.3)$ & $2(2.4)$ \\
Local & $4(3.9)$ & $5(4.4)$ & $4(4.7)$ \\
Brain & $1(1.0)$ & & 3 \\
$\begin{array}{l}\text { Liver+lung } \\
\text { Liver+peritoneum }\end{array}$ & 1 & 1 & 1 \\
$\begin{array}{l}\text { Lung+lymph node } \\
\text { Peritoneum+lymph node+ } \\
\text { local }\end{array}$ & & 1 & $33(38.8)^{*}$ \\
Total & $21(20.4)$ & $35(31.0)$ & \\
\hline
\end{tabular}

*Total recurrence rate was higher in the TADT group than in the Surgery group $(p=0.006$, OR $0.470,95 \%$ Conf. int. $0.211,0.772$ ) 
In this study, we analyzed RFS as a primary endpoint. The SEMS placement as BTS with curative intent in OLCRC was not associated with impaired long-term oncologic outcomes when compared to the Surgery group, but the TADT group had poor outcomes. The 3-year RFS rate in patients with the SEMS group $(69.0 \%)$ was not statistically significant compared to those with the Surgery group (74.8\%). A similar study from Korea, comparing the emergency surgery and the BTS by SEMS reported that the 5-year disease-free survival (DFS) of stage II and III was $51.6 \%$ for emergency surgery and $63.3 \%$ for SEMS without statistical significance [17]. However, another similar study in Spain reported that 5-year progression-free survival of stage III was $69.7 \%$ for SEMS and $30.0 \%$ for emergency surgery with significant difference [22]. Meta-analysis reported that stent placement before elective surgery did not adversely affect overall survival and disease-free survival, and there was no significant difference between the randomized and observational studies [23], and ESCO trial from Italy [18] also reported no difference in DFS between the emergency surgery and the BTS by SEMS placement. In the Dutch study [19], when the enrolled cases with curative resection were analyzed, the 3-year DFS was $52.6 \%$ in the emergency surgery and $58.8 \%$ in the BTS using SEMS, showing no difference in long-term oncological outcomes. Our results were in accordance with these data. On the other hand, the RFS rate in patients with the TADT group (59.2\%) was significantly lower than that in patients with the Surgery group (74.8\%). This result might be associated with tumor locations and stages. Comparing the patient characteristics, the ratio of patients with upper rectal cancer in the TADT group was approximately twice as higher than that in the Surgery group. It may likely explain the poor prognosis in the TADT group. A subgroup analysis was then performed to exclude upper rectal cancer. As a result, RFS rate of the TADT group tended to be poorer than that of the Surgery group. The ratio of patients with Stage III in the TADT group was significantly higher than that in the Surgery group. There was no significant difference in RFS between each treatment groups in Stage II patients, but RFS rate of Stage III patients in the TADT group was significantly poorer than that in Surgery group. It can be also explained by the poor prognosis in the TADT group. In the present study, induction rates of adjuvant chemotherapy were not different between each treatment groups, although a lower induction rate has been expected in the Surgery group due to postoperative complications. There was also no difference in induction rates of adjuvant chemotherapy in the reports from Korea and the Netherlands $[17,19]$.

The patients were enrolled from twenty-seven Japanese centers in this study. These data may approximate real-world data, although there was some variability in treatment strategies. The demographical characteristics show that the median follow-up period was 46.2 months of the SEMS group, which was equal or longer than that reported from the Netherlands
[19] and cannot be considered to be of short duration. The patients of the Surgery group had better PS than that of the SEMS group and the TADT group. This seems to be a reasonable result for a retrospective observational study. A previous study [19] had reported that emergency surgery was performed to younger patients and SEMS to older patients, but this could have been due to a difference in PS rather than age, in this study. The proportion of upper rectum cases tended to be higher in the TADT group than other groups. Emergency surgery was less preferred for upper rectum because of longer operative time, the higher incidence of postoperative complications especially anastomotic leakage. The SEMS group had less upper rectum cases as it is associated with complications such as pain, tenesmus, incontinence, and stent migration, and fear that the inflammation of the anal side of rectum by SEMS would make radical surgery difficult [21, $24,25]$.

A number of meta-analyses have reported favorable shortterm results for SEMS compared to emergency surgery in terms of temporary/permanent stoma rates, primary anastomosis rates, and postoperative complications, including anastomotic leakage [16, 20, 26, 27]. The success rate of stent placement was low causing poor prognosis for BTS by stent placement [28], but in recent years, the success rate had improved [29]. A report from the Netherlands [19] found no difference in the long-term prognosis of emergency surgery and BTS by SEMS and described that SEMS had technical success of $87.5 \%$ with clinical success of $81.1 \%$. In the present study, the technical and clinical success rates for SEMS placement were $99.1 \%$ and $97.3 \%$, respectively, and these were likely to be improved because of the JCSSPRG mini-guidelines. Although the results of this study may not support the association between stent related microperforation and dissemination of tumor cells, our findings emphasize that SEMS placement as a BTS may be safely performed with experienced endoscopists. An epidemiological study using the Japanese Diagnosis Procedure Combination database showed that SEMS patients are inferior to emergency surgery patients in overall survival rate [30]. However, in that study, the success rate of SEMS placement was unknown, it was evaluated by overall survival rate, and it had a short follow-up period of 14.9 months for SEMS and 14.7 months for emergency surgery, which may have influenced the results.

TADT was one of decompression methods of BTS for OLCRC since the 1990s because SEMS was not being covered by insurance system in Japan. But there has been no consensus on the evaluation of TADT, and it is still controversial $[6,31]$. Although TADT is considered to have a negative impact on QOL, the expenses of TADT is much lower than that of SEMS. For these reasons, TADT has been used as a procedure of BTS in some Asian countries [32, 33]. In a meta-analysis comparing the success rates, both technical and clinical success rates were significantly better for SEMS than 
for TADT [6]. This meta-analysis also reported significantly better tumor resection rates, primary anastomosis rates, stoma rates for SEMS, and trend to benefit in the SEMS than in the TADT for complications related to decompression including perforation (though the difference was not significant). Postoperative complications rates, including anastomotic leakage, surgical site infection, and ileus, were similar. The postoperative hospital stay was shorter with SEMS, but the difference did not reach significance. In terms of long-term outcomes, the 5-year DFS of stage II and III was reported to be $72.2 \%$ for SEMS and $52.0 \%$ for TADT [33].

Our result suggested that total recurrence rate in the SEMS group tended to be higher than that in the Surgery group. There are few detailed reports on the sites of recurrence. There was no difference between the SEMS and the emergency surgery in locoregional recurrence, including peritoneal metastasis, in reports where recurrence sites were described $[17,19]$. This may be due to the low rate of complications such as perforation during stent placement. The frequency of hematogenous metastases compiled from reports of OLCRC did not differ, being $26.1 \%$ by SEMS and $32.2 \%$ by emergency surgery, respectively [19]. This is similar to the results of our study. A study comparing recurrence rates in SEMS and TADT [21] reported no significant difference in locoregional spread with rate of $1.9 \%$ and $13.0 \%$, respectively, or hematogenous spread with rates of $20.8 \%$ and $21.7 \%$, respectively, but this study had small sample size (76 cases), and it is possible that the assessment of locoregional recurrence could have changed if the number of cases increased.

This study has several limitations that must be taken into account. First, even though this study is a multicenter study, it is a retrospective study. The indication for SEMS insertion before a radical surgery was not strictly like that in other retrospective studies. Although considering the obstacles, such as the requirement of large sample size, emergency setting, and the difficulty in technical standardization, pursuing a multicenter RCT on this topic seems difficult, and JCSSPRG has been currently conducting RCT, the results of which are awaited. Second, the procedure for the SEMS placement was based on mini-guidelines but no procedure was defined for the TADT placement. Third, type of SEMS (lumen diameter, etc.) used for BTS in this study was not determined. Fourth, only patients who underwent colonic resection were included in this study. Thus, patients who died as a consequence of SEMS placement and TADT placement remained beyond the scope of the present study. However, as no postoperative deaths after SEMS placement have been reported in any previous reporting on SEMS as BTS, the influence of this shortcoming is expected to be negligible. In this study, long-term outcome was assessed by the RFS as a primary endpoint. Due to the significant advances in therapeutic chemotherapy in recent years, we believe that there would be no difference in long-term outcome based on the overall survival. There is also an option to evaluate the propensity score matching method, but due to the small number of cases enrolled, we evaluated all cases included in this study.

\section{Conclusion}

This study suggests that SEMS placement followed by surgery, has no adverse influence in terms of the patient relapse-free survival, compared with emergency surgery. Additionally, total number of complications after curative surgery were significantly lower in the SEMS group than the Surgery group. SEMS placement performed by experienced endoscopist, can be a treatment option for OLCRC as well as emergency surgery.

Acknowledgments The authors thanks S Shimizu (Tokyo Women's Medical University) for advice and help with the statistical analyses. The participating members from the Japan Colonic Stent Safe Procedure Research Group are follows: Dr. K. Takayasu (Kyorin University), Dr. Y Kadono (Saiseikai Kumamoto Hospital), Dr. K Amano (Saitama Medical University), Dr. H. Otsuka (Tokyo Metropolitan Tama Medical Center), Dr. T Fujimoto (Kimitsu Chuo Hospital), Dr. H Egashira (Shonan Kamakura General Hospital), Dr. M Ushigome (Toho University Omori Medical Center), Dr. M Ebi (Aichi Medical University School of Medicine), Dr. Y Sumida (Kyusyu Medical Center), Dr. S Asai (Tane General Hospital), Dr. K Nasu (Tokyo Metropolitan Bokutoh Hospital), Dr. T Shiratori (Kameda Medical Center), Dr. T Kawamura (Kyoto Second Red Cross Hospital), Dr. T Ohki (Tokyo Women's Medical University), Dr. H Naota (Matsusaka Chuo General Hospital), Dr. H Matsushita (Japanese Red Cross Akita Hospital), Dr. N Watanabe (Mie Chuo Medical Center), Dr. A Kohyama (Japanese Red Cross Ishinomaki Hospital), Dr. T Kuwai (Kure Medical Center and Chugoku Cancer Center), Dr. S Saito (Yokohama ShinMidori General Hospital), Dr. K Ohta (Higashiosaka City Medical Center), Dr. T Kimura (Tsuruga Medical Center), Dr. O Okamura (Suita Municipal Hospital).

Author contributions Shungo Endo, Kensuke Kumamoto, Toshiyuki Enomoto, Koichi Koizumi, Hiroyuki Kato, and Yoshihisa Saida meet all the criteria for the definition of authorship and contributed substantially to the manuscript. Shungo Endo is the correspondent author.

\section{Compliance with ethical standards}

Conflict of interest The authors declare that they have no conflict of interest.

Ethics approval This study was approved by the Ethics Committee of the Fukushima Medical University.

Code availability Microsoft Word 2016.

Open Access This article is licensed under a Creative Commons Attribution 4.0 International License, which permits use, sharing, adaptation, distribution and reproduction in any medium or format, as long as you give appropriate credit to the original author(s) and the source, provide a link to the Creative Commons licence, and indicate if changes were made. The images or other third party material in this article are included in the article's Creative Commons licence, unless indicated otherwise in a credit line to the material. If material is not included in the article's Creative Commons licence and your intended use is not permitted by 
statutory regulation or exceeds the permitted use, you will need to obtain permission directly from the copyright holder. To view a copy of this licence, visit http://creativecommons.org/licenses/by/4.0/.

\section{References}

1. Jemal A, Bray F, Center MM, Ferlay J, Ward E, Forman D (2011) Global cancer statistics. CA Cancer J Clin 61(2):69-90. https://doi. org/10.3322/caac.20107

2. Jullumstro E, Wibe A, Lydersen S, Edna TH (2011) Colon cancer incidence, presentation, treatment and outcomes over 25 years. Color Dis 13:512-518. https://doi.org/10.1111/j.1463-1318.2010. 02191.x

3. Yeo HL, Lee SW (2013) Colorectal emergencies; review and controversies in the management of large bowel obstruction. J Gastrointest Surg 17:2007-2012. https://doi.org/10.1007/s11605013-2343-x

4. Yang Z, Wang L, Kang L, Xiang J, Peng J, Cui J, Huang Y, Wang J (2011) Clinicopathologic characteristics and outcomes of patients with obstructive colorectal cancer. J Gastrointest Surg 15:12131222. https://doi.org/10.1007/s11605-011-1563-1

5. Lelcuk S, Ratan J, Klausner JM, Skornick Y, Merhav A, Rozin RR (1986) Endoscopic decompression of acute colonic obstruction. Avoiding staged surgery. Ann Surg 203:292-294. https://doi.org/ 10.1097/00000658-198603000-00013

6. Matsuda A, Yamada T, Matsumoto S, Sakurazawa N, Kawano Y, Sekiguchi K, Matsutani T, Miyashita M, Yoshida H (2019) Shortterm outcomes of a self-expandable metallic stent as a bridge to surgery vs. a transanal decompression tube for malignant largebowel obstruction: a meta-analysis. Surg Today 49(9):728-737. https://doi.org/10.1007/s00595-019-01784-y

7. Dohmoto M, Hünerbein M, Schlag PM (1997) Application of rectal stents for palliation of obstructing rectosigmoid cancer. Surg Endosc 11(7):758-761. https://doi.org/10.1007/s004649900444

8. van Hooft JE, van Halsema EE, Vanbiervliet G, Beets-Tan RG, DeWitt JM, Donnellan F, Dumonceau JM, Glynne-Jones RG, Hassan C, Jiménez-Perez J, Meisner S, Muthusamy VR, Parker MC, Regimbeau JM, Sabbagh C, Sagar J, Tanis PJ, Vandervoort J, Webster GJ, Manes G, Barthet MA, Repici A (2014) European Society of Gastrointestinal Endoscopy. Self-expandable metal stents for obstructing colonic and extracolonic cancer: European Society of Gastrointestinal Endoscopy (ESGE) clinical guideline. Endoscopy 46(11):990-1053. https://doi.org/10.1055/s-00341390700

9. Tomita M, Saito S, Makimoto S, Yoshida S, Isayama H, Yamada T, Matsuzawa T, Enomoto T, Kyo R, Kuwai T, Hirata N, Shimada M, Hirakawa T, Koizumi K, Saida Y (2019) Self-expandable metallic stenting as a bridge to surgery for malignant colorectal obstruction: pooled analysis of 426 patients from two prospective multicenter series. Surg Endosc 33(2):499-509. https://doi.org/10.1007/ s00464-018-6324-8

10. Katayama H, Kurokawa Y, Nakamura K, Ito H, Kanemitsu Y, Masuda N, Tsubosa Y, Satoh T, Yokomizo A, Fukuda H, Sasako M (2016) Extended Clavien-Dindo classification of surgical complications: Japan clinical oncology group postoperative complications criteria. Surg Today 46(6):668-685. https://doi.org/10.1007/ s00595-015-1236-x

11. Matsuzawa $T$, Ishida $H$, Yoshida $S$, Isayama $H$, Kuwai $T$, Maetani I, Shimada M, Yamada T, Tomita M, Koizumi K, Hirata N, Kanazawa H, Enomoto T, Sekido H, Saida Y (2015) A Japanese prospective multicenter study of self-expandable metallic stent placement for malignant colorectal obstruction: short term safety and efficacy within 7 days of stent procedure in 513 cases. Gastrointest Endosc 82(4):697-707. https://doi.org/10.1016/j.gie. 2015.03.1978

12. Watanabe T, Itabashi M, Shimada Y, Tanaka S, Ito Y, Ajioka Y, Hamaguchi T, Hyodo I, Igarashi M, Ishida H, Ishiguro $M$, Kanemitsu Y, Kokudo N, Muro K, Ochiai A, Oguchi M, Ohkura Y, Saito Y, Sakai Y, Ueno H, Yoshino T, Fujimori T, Koinuma N, Morita T, Nishimura G, Sakata Y, Takahashi K, Takiuchi H, Tsuruta O, Yamaguchi T, Yoshida M, Yamaguchi N, Kotake K, Sugihara K (2012) Japanese Society for Cancer of the Colon and Rectum. Japanese Society for Cancer of the Colon and Rectum (JSCCR) guidelines 2010 for the treatment of colorectal Cancer. Int J Clin Oncol 17(1):1-29. https://doi.org/10.1007/s10147-0110315-2

13. Pirlet IA, Slim K, Kwiatkowski F, Michot F, Millat BL (2011) Emergency preoperative stenting versus surgery for acute leftsided malignant colonic obstruction: a multicenter randomized controlled trial. Surg Endosc 25(6):1814-1821. https://doi.org/10. 1007/s00464-010-1471-6

14. van Hooft JE, Bemelman WA, Oldenburg B, Marinelli AW, Lutke Holzik MF, Grubben MJ, Sprangers MA, Dijkgraaf MG, Fockens P, collaborative Dutch Stent-In study group (2011) Colonic stenting versus emergency surgery for acute left-sided malignant colonic obstruction: a multicentre randomised trial. Lancet Oncol 12(4): 344-352. https://doi.org/10.1016/S1470-2045(11)70035-3

15. Saito S, Yoshida S, Isayama H, Matsuzawa T, Kuwai T, Maetani I, Shimada M, Yamada T, Tomita M, Koizumi K, Hirata N, Kanazawa H, Enomoto T, Sekido H, Saida Y (2016) A prospective multicenter study on self-expandable metallic stents as a bridge to surgery for malignant colorectal obstruction in Japan: efficacy and safety in 312 patients. Surg Endosc 30(9):3976-3986. https://doi. org/10.1007/s00464-015-4709-5

16. Yang SY, Park YY, Han YD, Cho MS, Hur H, Min BS, Lee KY, Kim NK (2019) Oncologic outcomes of self-expandable metallic stent as a bridge to surgery and safety and feasibility of minimally invasive surgery for acute malignant colonic obstruction. Ann Surg Oncol 26(9):2787-2796. https://doi.org/10.1245/s10434-01907346-3

17. Arezzo A, Balague C, Targarona E, Borghi F, Giraudo G, Ghezzo L, Arroyo A, Sola-Vera J, De Paolis P, Bossotti M, Bannone E, Forcignanò E, Bonino MA, Passera R, Morino M (2017) Colonic stenting as a bridge to surgery versus emergency surgery for malignant colonic obstruction: results of a multicentre randomised controlled trial (ESCO trial). Surg Endosc 31(8):3297-3305. https:// doi.org/10.1007/s00464-016-5362-3

18. Amelung FJ, Borstlap WAA, Consten ECJ, Veld JV, van Halsema EE, Bemelman WA, Siersema PD, Ter Borg F, van Hooft JE, Tanis PJ, Dutch Snapshot Research Group (2019) Propensity scorematched analysis of oncological outcome between stent as bridge to surgery and emergency resection in patients with malignant leftsided colonic obstruction. BJS 106(8):1075-1086. https://doi.org/ $10.1002 /$ bjs. 11172

19. Allievi N, Ceresoli M, Fugazzola P, Montori G, Coccolini F, Ansaloni L (2017) Endoscopic stenting as bridge to surgery versus emergency resection for left-sided malignant colorectal obstruction: an updated meta-analysis. Int J Surg Oncol 2017:28632722863211. https://doi.org/10.1155/2017/2863272

20. Matsuda A, Miyashita M, Matsumoto S, Matsutani T, Sakurazawa N, Takahashi G, Kishi T, Uchida E (2015) Comparison of longterm outcomes of colonic stent as "bridge to surgery" and emergency surgery for malignant large-bowel obstruction: a meta-analysis. Ann Surg Oncol 22(2):497-504. https://doi.org/10.1245/s10434014-3997-7

21. van Hooft JE, Veld JV, Arnold D, Beets-Tan RGH, Everett S, Götz M, van Halsema EE, Hill J, Manes G, Meisner S, Rodrigues-Pinto E, Sabbagh C, Vandervoort J, Tanis PJ, Vanbiervliet G, Arezzo A 
(2020) Self-expandable metal stents for obstructing colonic and extracolonic cancer: European Society of Gastrointestinal Endoscopy (ESGE) guideline - update 2020. Endoscopy 52(5): 389-407. https://doi.org/10.1055/a-1140-3017

22. Lara-Romero C, Vilches Á, Caunedo-Álvarez Á, HerguetaDelgado P, Lavín-Castejón I, Andrade-Bellido R, AlcaínMartínez G (2019) Better recurrence-free survival after stent bridge to surgery compared to emergency surgery for obstructive leftsided colonic cancer in patients with stage III status of the American Joint Committee on Cancer (AJCC): a bicentric retrospective stud. Int J Color Dis 34(7):1241-1250. https://doi.org/10. 1007/s00384-019-03318-x

23. Cao Y, Gu J, Deng S, Li J, Wu K, Cai K (2019) Long-term tumour outcomes of self-expanding metal stents as 'bridge to surgery' for the treatment of colorectal cancer with malignant obstruction: a systematic review and meta-analysis. Int J Color Dis 34(11): 1827-1838. https://doi.org/10.1007/s00384-019-03372-5

24. Zhang Y, Shi J, Shi B, Song CY, Xie WF, Chen YX (2012) Selfexpanding metallic stent as a bridge to surgery versus emergency surgery for obstructive colorectal cancer: a meta-analysis. Surg Endosc 26(1):110-119. https://doi.org/10.1007/s00464-011-18356

25. Song HY, Kim JH, Kim KR, Shin JH, Kim HC, Yu CS, Kim JC (2008) Malignant rectal obstruction within $5 \mathrm{~cm}$ of the anal verge: is there a role for expandable metallic stent placement? Gastrointest Endosc 68(12):713-720. https://doi.org/10.1016/j.gie.2007.12.051

26. Arezzo A, Passera R, Lo Secco G, Verra M, Bonino MA, Targarona E, Morino M (2017) Stent as bridge to surgery for leftsided malignant colonic obstruction reduces adverse events and stoma rate compared with emergency surgery: results of a systematic review and meta-analysis of randomized controlled trials. Gastrointest Endosc 86(3):416-426. https://doi.org/10.1016/j.gie. 2017.03.1542

27. Huang X, Lv B, Zhang S, Meng L (2014) Preoperative colonic stents versus emergency surgery for acute left-sided malignant colonic obstruction: a meta-analysis. J Gastrointest Surg 18(3):584591. https://doi.org/10.1007/s11605-013-2344-9
28. Sabbagh C, Browet F, Diouf M, Cosse C, Brehant O, Bartoli E, Mauvais F, Chauffert B, Dupas JL, Nguyen-Khac E, Regimbeau JM (2013) Is stenting as "a bridge to surgery" an oncologically safe strategy for the management of acute, left-sided, malignant, colonic obstruction? A comparative study with a propensity score analysis. Ann Surg 258(1):107-115. https://doi.org/10.1097/SLA. 0b013e31827e30ce

29. Yoon JY, Jung YS, Hong SP, Kim TI, Kim WH, Cheon JH (2011) Clinical outcomes and risk factors for technical and clinical failures of self-expandable metal stent insertion for malignant colorectal obstruction. Gastrointest Endosc 74(4):858-868. https://doi.org/ 10.1016/j.gie.2011.05.044

30. Katsuki R, Jo T, Yasunaga H, Ishimaru M, Sakamoto T (2020) Outcomes of self-expandable metal stent as bridge to surgery versus emergency surgery for left-sided obstructing colon cancer: a retrospective cohort study. Am J Surg S0002-9610(20):30364-30360. Online ahead of print. https://doi.org/10.1016/j.amjsurg.2020.06. 012

31. Sato R, Oikawa M, Kakita T, Okada T, Oyama A, Abe T, Yazawaw T, Tsuchiya H, Akazawa N, Ohira T, Harada Y, Tanaka M, Okano H, Ito K, Tsuchiya T (2019) Comparison of the long- term outcomes of the self- expandable metallic stent and transanal decompression tube for obstructive colorectal cancer. Ann Gastroenterol Surg 3(2):209-216. https://doi.org/10.1002/ags3.12235

32. Zhang N, Zhou ZL, Xie JL (2015) Application of Transanal ileus tube in acute obstructive left-sided colorectal Cancer. Int J Clin Exp Med 8(8):147024-114029

33. Kagami S, Funahashi K, Ushigome M, Koike J, Kaneko T, Koda T, Kurihara A, Nagashima Y, Yoshino Y, Goto M, Mikami T, Chino K (2018) Comparative study between colonic metallic stent and anal tube decompression for Japanese patients with left-sided malignant large bowel obstruction. World J Surg Oncol 16(1):210. https://doi.org/10.1186/s12957-018-1509-0

Publisher's note Springer Nature remains neutral with regard to jurisdictional claims in published maps and institutional affiliations. 